\title{
UAV and Artificial Intelligence in Precision Viticulture
}

\author{
Gambella F* \\ Department of Agricultural Science, University of Sassari, Italy
}

Submission: May 05, 2018; Published: May 31, 2018

"Corresponding author: Gambella Filippo, Senior researcher, Department of Agricultural Science Viale Italia 39, 07100, University of Sassari, Italy, Tel: +39 079229281; Email: gambella@uniss.it

\begin{abstract}
Precision viticulture and the use of monitoring systems for the management of spatial and temporal variability in recent decades has been the research topic that has led to the emergence of new high tech production segments that have been able to accompany the transformation of agricultural machines. The results of the research have enabled the design and introduction of autonomous vehicles (drones) and intelligent sensors, suitable for proximal and remote sensing and for use in the sustainable management of the vineyard. At the same time, there are still difficulties in market deployment of these technologies due to high costs and difficult integration with ordinary agronomic techniques. The object of this mini-review is to present the innovative technologies applied in precision viticulture considering several key words: vineyard management, UAV and Machine learning technologies.
\end{abstract}

Keywords: Vineyard management, UAV and Machine learning technologies

Abbreviations: UAV: Unmanned Aerial Vehicle; PV: Precision Viticulture; ExG: Excess Green Index; CIVE: Colour Index of Vegetation Extraction; NGRDI: Normalized Green-Red Difference Index.

\section{Introduction}

In general, assessment of spatial variability of crop physiological variables is a prerequisite for the application of precision viticulture techniques. Monitoring the vineyard with "traditional methods" require high labour demanding, high time-consuming and in some cases had a low accuracy. In the context of vineyard and wine process management, several studies show the importance of the use of Unmanned Aerial Vehicle (UAV) and Artificial Intelligence as novel tools used for vineyard management, early pest detection, estimate the growth stage and the potential quality of vine grapes. Unmanned Aerial Vehicle equipped with RGB and NIR camera are commonly use in precision Viticulture (PV). These techniques are used for obtain colour index-based approaches such us Normalised Difference Index (NDI), Excess Green Index (ExG), Excess Red Index (ExR), colour Index of Vegetation Extraction (CIVE), Excess Green minus Excess Red Index (ExGR), Normalised Green-Red Difference Index (NGRDI), Vegetative Index (VEG) or combined indices such us Modified Excess Green Index (MExG). These indices are often use in order to segment the green vegetation regions in agriculture remote sensing images. Vegetative indices, color estimation, shape and size analyses are features for which image analysis provides an objective and reliable tool. Machine vision has many potential applications in viticulture, as a rapid and practical method to estimate canopy features in the field.
In viticulture, cluster morphology and berry size are two key parameters, which not only impact the cluster architecture and compactness (leading to looser or tighter clusters), but are also considered as indicators of grape and wine quality $[1,2]$. Recently, the acquisition of high resolution RGB images of the canopy from UAV joint to Structure from Motion (SfM) technique has proved to be an effective tool for estimating plant architecture through the computation of a Digital Surface Model (DSM) [3-5]. Machine Learning (ML) techniques combined with machine vision technology has been widely used and studied in agriculture to identify and detect plants (crops \& weeds), which proposed to Berenstein et al. [6] that proposed a method of grape and foliage detection by specific algorithms for an autonomous selective vineyard sprayer. It has shown a potential for success in a number of case studies in robotic weed control systems despite some serious challenges. Slaughter et al. [7] developing image-processing methods as guidance for machine vision, working in different fields and environments (under controlled and uncontrolled conditions). After many decades of study, machine vision has improved the quality management of weed control systems [8,9]. Different algorithms and techniques i.e. unsupervised fuzzy clustering algorithms, mean-shift-based learning procedure, convolutional neural network, Deep Neural Networks, [10] are proposed for detection and classification of weed plant. Machine vision technology, guided by ML, also been 
applied in other aspect of the viticulture, such as grading fruits, Liu et al. [11] proposed a computer vision system for early stage grape yield estimation based on shoot detection. Ivorra $\mathrm{E}$ et al. [12] identified grape cluster yield components based on 3D descriptors. Cubero et al. [13] propose a method for detection and size assessment of grapevine berries by pedicel/peduncle evolution and Roscher et al. [14], using conditional random fields present an automated image analysis framework for high-throughput determination of grapevine berry sizes. For precision harvest through computer vision and image-based color analysis Pothen \& Nuske [15] proposed an automated approach for evaluating color development to grade and predict the color development of grape clusters in the vineyard. Using this approach, the authors generate spatial maps of the vineyard showing the current and predicted distribution of color development [16-20].

\section{Conclusion}

In conclusion, UAV, computer vision techniques and artificial intelligence are technologies that a large number of researchers had applied in the evaluation of crop physiological variables and in the analysis of temporal e spatial variability. The demand of new technologies in viticulture increase year by year, the application of this new perspective in the agricultural field is mature. The high number of scientific work, national and international congress, specific conference and workshop dedicate to the introduction of the new management of the vineyard by application of Precision Viticulture demonstrate the validity of the methodologies applied and utilized in viticulture. Utilizing the technologies a new challenge started for to the viticulture the possibility to apply the new paradigm proposed by the Precision agriculture, do the right thing, at the right time in the right place.

\section{References}

1. Roby G, Harbertson JF, Adams Douglas A, Matthews MA (2004) Berry size and vine water deficits as factors in wine grape composition: Anthocyanins and tannins. Australian Journal of Grape and Wine Research 10(2): 100-107.

2. Matthews MA, Nuzzo V (2007) Berry size and yield paradigms on grapes and wines quality. Acta Horticulture 754: 423-436.

3. Torres-Sanchez J, Lopez-Granados F, Pena JM (2015) An automatic object-based method for optimal thresholding in UAV images: Application for vegetation detection in herbaceous crops. Computers and Electronics in Agriculture 114: 43-52.

4. Ballesteros R, Ortega JF, Hernández D, Moreno MÁ (2015) Characterization of Vitis vinifera L. Canopy Using Unmanned Aerial Vehicle-Based Remote Sensing and Photogrammetry Techniques. American Journal of Enology and Viticulture 66: 120-129.
5. Moriondo M, Leolini L, Staglianò N, Argenti G, Trombi G, et al. (2016) Use of digital images to disclose canopy architecture in olive tree. Scientia Horticulturae 209: 1-13.

6. Berenstein R, Shahar BO, Shapiro A, Edan Y (2010) Grape clusters and foliage detection algorithms for autonomous selective vineyard sprayer. Intel Serv Robotics (2010) 3(4): 233-243.

7. Slaughter DC, Giles DK, Downey D (2008) Autonomous robotic weed control systems: A review. Computers and electronics in agriculture 61(1): 63-78.

8. Meyer GE, Mehta T, Kocher F, Mortensen DA, Samal A (1998) Textural imaging and discriminant analysis for distinguishing weeds for spot spraying. Trans. ASAE 41(4): 1189-1197.

9. Onyango CM, Marchant JA (2003) Segmentation of weeds from plants using colour and morphology. Computers and Electronics in Agriculture 39(3): 141-155.

10. Sladojevic S, Arsenovic M, Anderla A, Culibrk D, Stefanovic D (2016) Deep Neural Networks, Based Recognition of Plant Diseases by Leaf Image Classification. Computational Intelligence and Neuroscience.

11. Liu S, Cossell S, Tang J, Dunn G, Whitty M (2017) A computer vision system for early stage grape yield estimation based on shoot detection. Computers and Electronics in Agriculture 137: 88-101.

12. Ivorra E, Sanchez AJ, Camarasa JG, Diago MP, Tardaguila J (2015) Assessment of grape cluster yield components based on 3D descriptors using stereo vision. Food Control 50: 273-282.

13. Cubero S, Diago PM, Blasco J, Tardàguila J, Millàn B, et al. (2014) A new method for pedicel/peduncle detection and size assessment of grapevine berries and other fruits by image analysis. Biosystems Engineering 117: 62-72.

14. Roscher R, Herzog K, Kunkel A, Kicherer A, Topfer R, et al. (2014) Automated image analysis framework for high-throughput determination of grapevine berry sizes using conditional random fields. Computers and Electronics in Agriculture 100: 148-158.

15. Pothen Z, Nuske S (2016) Automated Assessment and Mapping of Grape Quality through Image-based Color Analysis. IFAC-Papers On Line 49(16): 72-078.

16. Sogaard HT (2005) Weed classification by active shape models. Biosyst Eng 91(3): 271-281.

17. Sankaran S, Mishra A, Ehsani R, Davis C (2010) A review of advanced techniques for detecting plant diseases. Computers and Electronics in Agriculture 72(1): 1-13.

18. Davies G, Casady W, Massey R (1998) Precision agriculture: An introduction. Water Quality Focus Guide.

19. Sankarana S, Mishraa A, Ehsania R, Davis C (2010) A review of advanced techniques for detecting plant diseases. Computers and Electronics in Agriculture 72(1): 1-13.

20. Roberts MJ, Schimmelpfennig D, Ashley E, Livingston M, Ash M (2006) The value of plant disease early-warning systems. Economic Research Service No. 18, United States Department of Agriculture, USA. 


\section{Your next submission with Juniper Publishers} will reach you the below assets

- Quality Editorial service

- Swift Peer Review

- Reprints availability

- E-prints Service

- Manuscript Podcast for convenient understanding

- Global attainment for your research

- Manuscript accessibility in different formats ( Pdf, E-pub, Full Text, Audio)

- Unceasing customer service

Track the below URL for one-step submission https://juniperpublishers.com/online-submission.php 